Kajian Ilmiah Mata Kuliah Umum

Volume 15 Nomor 1, September 2015

Penerbit
Pelindung dan Penasehat
Penanggung Jawab
Pemimpin Umum
Penyunting Ahli
Pemimpin Redaksi
Sekretaris Redaksi
Anggota Redaksi

Sekretariat
: Pusat MKU Universitas Negeri Yogyakarta

: Wakil Rektor I UNY

: Wawan S. Suherman

: Sunarso

: Marzuki

: Rukiyati

: Vita Fitria

: Sri Agustin Sutrisnowati, Amir Syamsudin, Syukri Fathudin Achmad Widdodo,

Benni Setiawan

: Ari Saraswati

Alamat Redaksi/Tata Usaha:
Pusat MKU UNY, Gedung LPPMP Lt.3 Sayap Timur
Kampus Karangmalang Yogyakarta
Email: mku@uny.ac.id, mku.uny@gmail.com, ruki1961@yahoo.com

HUMANIKA Kajian Ilmiah Mata Kuliah Umum menerima kiriman tulisan/artikel yang terkait dengan Mata Kuliah Umum (MKU), yang meliputi Pendidikan Agama, Pendidikan Pancasila, Pendidikan Kewarganegaraan, Ilmu Sosial Dasar, Ilmu Budaya Dasar, Ilmu Alamiah Dasar, dan Pendidikan Kependudukan dan Lingkungan Hidup, dengan ketentuan sebagai berikut:

1. Naskah dapat berupa hasil penelitian atau artikel ilmiah bebas dan belum pernah diterbitkan.

2. Naskah diketik dengan spasi satu setengah (1,5 spasi) dengan jumlah halaman 1015 halaman kuarto, diketik dengan MS Word ukuran font 12 Times New Roman.

3. Naskah memuat komponen: judul ( $<10 \mathrm{kata})$, nama penulis, alamat email, abstrak (100-150 kata), isi karangan (yang memuat pendahuluan, pembahasan, kesimpulan) dan daftar pustaka.

4. Naskah dikirim dalam bentuk print out dan soft copy.

5. Daftar pustaka ditulis secara alfabetis seperti berikut:

- Hidayat, Komaruddin. 2004. Menafsir Kehendak Tuhan. Jakarta: Serambi.

- Bagir, Haidar. 2012. "Syiah dan Kerukunan Umat". Republika. 20 Januari. 


\section{DAFTAR ISI}

Redaksi Humanika ........................................................................... i

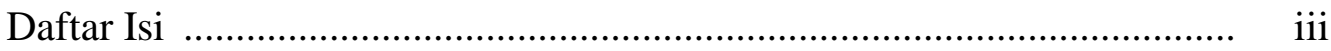

Pengantar Redaksi ...........................................................................

Islam Rahmah dan Wasathiyah

(Paradigma Keberislaman Inklusif, Toleran dan Damai)

Abd. Malik Usman........................................................................... 1-12

The Dialectics of Javanese and Islamic Cultures:

an Introduction to Kuntowijoyo's Thought

Pradana Boy ZTF

Persepsi Masyarakat Kotagede Terhadap Pengunaan Media Komunikasi oleh Organisasi Forum Joglo untuk Peletarian Budaya di Kotagede

Yogyakarta

Choirul Fajri

Implikasi Budaya Organisasi Terhadap Pola Perilaku Komunikasi

Kelompok Tani Sumber Rejeki

Mariana Ulfah dan Siti Chotijah

Etika Sosial dalam Kerukunan Umat Beragama

(Studi Kasus di Desa Kotesan Kecamatan Prambanan Kabupaten Klaten

Jawa Tengah)

Andy Dermawan dan Zunly Nadia

Model Komunikasi "Wom" Sebagai Strategi Pemasaran Efektif

Dani Fadillah

Mencari Model Pendidikan Karakter

Suparlan 


\title{
PERSEPSI MASYARAKAT KOTAGEDE TERHADAP PENGGUNAAN MEDIA KOMUNIKASI OLEH ORGANISASI FORUM JOGLO UNTUK PELESTARIAN BUDAYA DI KOTAGEDE YOGYAKARTA
}

\author{
Choirul Fajri \\ (Fajri/choirulfajri@yahoo.co.id) \\ Program Studi Ilmu Komunikasi \\ Universitas Ahmad Dahlan Yogyakarta
}

\begin{abstract}
Abstrak
Tujuan penelitian ini adalah untuk mengetahui persepsi masyarakat Kotagede terhadap penggunaan media komunikasi guna membantu melestarikan budaya oleh Organisasi Forum Joglo di Kotagede. Penelitian ini merupakan penelitian deskriptif. Data diperoleh melalui teknik angket, wawancara mendalam, observasi dan studi dokumen. Hasil penelitian menunjukkan adanya persepsi yang baik dari masyarakat Kotagede terkait dengan penggunaan media komunikasi oleh Organisasi Forum Joglo. Persepsi yang baik itu memberikan pengaruh berupa tingkat partisipasi yang tinggi terhadap program-program yang dilaksanakan.
\end{abstract}

Kata kunci : persepsi, media komunikasi, OrganisasiForum Joglo, Kotagede

\section{PENDAHULUAN}

Kotagede merupakan salah satu wilayah yang terletak di selatan Kota Yogyakarta yang dulunya merupakan pusat pemerintahan Kerajaan Mataram Islam. Sebagai salah satu wilayah peninggalan kerajaan Mataram Islam di Kotagede, masih banyak dijumpai bangunan-bangunan kuno. Sebanyak 170 bangunan kuno ada di Kotagede yang diperkirakan di bangun antara tahun 1700 sampai 1930-an (www.initempatwisata.com). Di antara bangunan kuno tersebut adalah rumah tradisional, masjid, pasar, singgasana raja, dan makam. Hal tersebut tentunya menjadi daya tarik para wisatawan baik lokal maupun mancanegara untuk berkunjung ke Kotagede.

Selain peninggalan bangunanbangunan bersejarah di Kotagede juga terdapat seni kerajinan perak yang merupakan sebagian besar mata pencarian penduduknya. Di Kotagede juga banyak industri kecil yang memproduksi makanan tradisional seperti yangko, kipo, ukel, banjar, emping dan lainnya. Ini tentu saja menjadi sebuah paket komplet bagi para wisatawan untuk berkunjung di Kotaged. Selain dapat melihat bangunan bersejarah (heritage), para wisatawan juga dapat berbelanja perak bahkan melihat proses pembuatannya dan juga berbelanja makanan tradisional.

Akan tetapi daya tarik Kotagede sebagai salah satu kawasan budaya tersebut seolah menjadi hilang ketika gempa bumi melanda Yogyakarta di tahun 2006 silam. Saat itu banyak sekali bangunan-bangunan bersejarah yang rusak bahkan rubuh akibat gempa. Peristiwa tersebut, tentu berpengaruh 
terhadap minat para wisatawan untuk berkunjung ke Kotagede. Seolah ingin bangkit dari keterpurukan, masyarakat Kotagede dengan dibantu oleh fasilitator Java Reconstructions Fund (JRF) bekerja bersama untuk mengembalikan Kotagede sebagai salah satu kawasan pusaka.

Banyak program yang sudah dilakukan oleh JRF dalam masalah fisik (tangible), misalnya renovasi terhadap bangunan-bangunan cagar budaya, pembangunan ruang-ruang publik dan lainnya. Sementara dalam masalah non fisik (intangible) dilakukan dengan membentuk Organisasi Forum Joglo, yang mempunyai fungsi sebagai organisasi bagi masyarakat Kotagede untuk mengembangkan Kawasan Cagar Budaya (KCB) Kotagede.

Setelah berakhirnya program JRF pada tahun 2011 lalu, program-program pelestarian Kotagede dilanjutkan oleh Organisasi Forum Joglo tersebut. Saat ini Forum Joglo telah membuat berbagai program untuk mengembangan Kotagede, misalnya dengan adanya event tahunan berupa Festival Budaya Kotagede. Diharapkan dengan event tersebut masyarakat luas dapat lebih mengenal Kotagede. Selain itu, Forum Joglo juga sudah membuat berbagai media komunikasi, yang digunakan untuk mengenalkan Kotagede. Di antara media-media komunikas tersebut adalah poster, leaflet, website, dan jejaring sosial. Selama ini media komunikasi yang digunakan belum pernah dilakukan penelitian baik mengenai persepsi masyarakat terhadap media tersebut, keefektifannya, maupun evaluasi penggunaannya.
Berdasarkan pertimbangan tersebut, perlu diteliti persepsi masyarakat Kotagede terhadap penggunaan media komunikasi oleh Organisasi Forum Joglo dalam upaya melestarikan budaya Kotagede Yogyakarta.

\section{METODE PENELITIAN}

Penelitian ini adalah penelitian deskriptif kuantitatif dilengkapi dengan deskriptif kualitatif. Variabel penelitian adalah persepsi masyarakat Kotagede terhadap penggunaan media komunikasi sebagai pelestarian budaya oleh Organisasi Forum Joglo Kotagede Yogyakarta yang secara keseluruhan diukur dengan angket tertutup berbentuk pertanyaan. Jumlah item dalam angket secara keseluruhan sebanyak 23 butir pertanyaan dengan rincian: 5 butir pertanyaan untuk poster, leaflet: 5 butir pertanyaan, website: 7 butir pertanyaan, dan jejaring sosial: 6 butir pertanyaan. Pemberian skor 2 untuk pilihan Jawaban "Ya" dan skor 1 untuk "Tidak" sehingga diperoleh rentang minimum sampai maksimum adalah 23 - 46. Besar ukuran sampel adalah 100 responden.

\section{HASIL PENELITIAN DAN PEMBAHASAN}

Dari hasil penelitian diperoleh hasil skor minimum sebesar $=23$; skor maksimum $=46 ;$ sum $=3868$; dan mean $=38,68$. Deskripsi hasil penelitian persepsi masyarakat Kotagede terhadap penggunaan media komunikasi sebagai pelestarian budaya oleh Organisasi Forum Joglo Kotagede Yogyakarta, dapat dilihat pada tabel di bawah ini. 
Tabel 1. Persepsi Masyarakat Kotagede terhadap Penggunaan Media Komunikasi Sebagai Pelestarian Budaya

\begin{tabular}{|c|c|c|c|c|}
\hline No & Interval & Kategori & $\mathbf{f}$ & $\mathbf{\%}$ \\
\hline 1. & $41,5-46,0$ & Sangat Tinggi & 33 & 33 \\
\hline 2. & $36,9-41,4$ & Tinggi & 43 & 43 \\
\hline 3. & $32,3-36,8$ & Sedang & 12 & 12 \\
\hline 4. & $27,7-32,2$ & Rendah & 7 & 7 \\
\hline 5. & $23,0-27,6$ & Sangat Rendah & 5 & 5 \\
& & $\mathbf{1 0 0}$ & $\mathbf{1 0 0}$ \\
\hline
\end{tabular}

Berdasarkan tabel 4 dan gambar 1 di atas diketahui bahwa persepsi masyarakat Kotagede terhadap penggunaan media komunikasi sebagai pelestarian budaya oleh Organisasi Forum Joglo Kotagede Yogyakarta secara umum termasuk kategori tinggi.

Penelitian ini telah mendapatkan hasil dalam hal mengetahui persepsi masyarakat kotagede terhadap penggunaan media komunikasi sebagai pelestarian budaya oleh Organisasi Forum Joglo Kotagede Yogyakarta. Hasil penelitian yang menunjukkan kecenderungan berkategori "tinggi" menunjukkan bahwa respon masyarakat kotagede sangat baik dalam hal menanggapi penggunaan media komunikasi dari Organisasi Forum Joglo Kotagede Yogyakarta sebagai bagian dari kegiatan pelestarian budaya. Persepsi yang tinggi didasari oleh kesadaran yang tinggi dari masyarakat terhadap kegiatan pelestarian budaya.

Selanjutnya, berdasarkan wawancara dengan pengurus organisasi Forum Joglo diperoleh penjelasan bahwa mereka akan terus mengembangkan media komunikasi yang digunakan untuk membantu pencapaian tujuan organisasi yakni melestarikan budaya di Kotagede. Selama ini, banyak media-media komunikasi yang digunakan masih merupakan warisan dari JRF, seperti halnya leaflet maupun peta jelajah pusaka. Hal ini senada dengan yang disampaikan oleh Synt sebagai Ketua Forum Joglo:"Iya masih dari JRF, yang bikinan Forum Joglo ya baru poster. Liflet pernahkita distribusikan ke daerah-daerah terutama di Dinas Pariwisata baik Kota dan Bantul dan untuk DIY sudah kita distribusikan ke sana juga. Kalau ada tamu-tamu dari luar juga kita selalu berikan itu".

Sampai penelitian dilakukan, Forum Joglo sudah mempunyai beberapa jenis leaflet, seperti: leaflet profile organisasi, leaflet jelajah pusaka Kotagede, dan rencana pengembangan Kawasan Cagar Budaya (KCB) Kotagede. Pengembangan KCB merupakan kerjasama antara Dinas Kebudayaan DIY dengan Forum Joglo. Adanya leaflet ini diharapkan untuk memberikan informasi kepada masyarakat Kotagede akan rencana pengembangan Kotagede baik fisik maupun non fisik sehingga diharapkan masyarakat dapat memahami, dan memberikan dukungan terhadap upayaupaya pengembangan yang dilakukan oleh pemerintah dan organisasi Forum Joglo sebagai pelaksananya.

Berbagai media komunikasi yang selama ini dikelola oleh Forum Joglo memang masih banyak mengalami kendala dalam pengelolaannya. Salah satu kendala tersebut, adalah kurangnya sumber daya manusia. Mengingat organisasi ini adalah organisasi sosial, di mana anggotanya bersifat sukarela tanpa memperoleh bayaran sehingga 
berbagai kegiatan yang dilaksanakan, termasuk dalam pengelolaan media komunikasi ini sangat tergantung dari keaktifan dan kerelaan dari para anggotanya.

Jika dilihat website Forum Joglo, sebenarnya website ini cukup mendapat respon yang baik oleh masyarakat. Hal ini dapat dilihat dari jumlah pengunjungnya. Smpai saat ini website tersebut telah diakses sebanyak 444.912 pengguna dengan akses ratarata per minggu 2000 pengguna. ${ }^{1}$ Dari segi banyaknya pengunjung website www.kotagedeheritage.org memang mendapatkan respon yang cukup baik dari masyarakat, namun dari intensitas pemberitaan masih kurang dikelola dengan baik. Terlebih saat ini justru mengalami kevakuman, karena terakhir kali posting berita dilakukan pada tahun 2012.

Oleh karena itu, ke depan Forum Joglo mempunyai rencana untuk mengembangan website ini, atau justru membuat website baru. Sebagaimana yang disampaikan oleh Ketua Forum Joglo, sebagai berikut:"Iya, website itu nanti yang akan kita kelola lagi. Kita membuat lagi saja nanti, tapi siapa yang dapat menjadi adminnya? Siapa?".

Sementara itu, salah satu tokoh masyarakat di Kotagede (sebut saja Pak Karno) mempunyai pendapat tersendiri. Media komunikasi yang tepat digunakan oleh Forum Joglo adalah media konvensional berupa bulletin. Menurutnya, di Kotagede media konvensional masih cukup efektif mengingat masyarakat Kotagede masih banyak yang belum dapat menggunakan media baru sebagaimana dinyatakannya sebagai berikut.

"Menurut saya malah menggunakan sebuah bulletin, kalau teknologi itu kan tidak semua orang dapat mengaksesnya di Kotagede ini. Kalau bulletin, misalnya nanti dapat dibaca, terus digeletake dan nanti dapat dibaca lagi. Kalau saya masih percaya pada media konvensional seperti itu".

Berdasarkan apa yang disampaikan Pak Karno tersebut, nampaknya memang Forum Joglo harus senantiasa menggunakan berbagai jenis media komunikasi. Setiap media komunikasi mempunyai karakteristik sendiri, oleh karenanya satu jenis media komunikasi saja, tidak akan cukup untuk memenuhi kebutuhan masyarakat Kotagede untuk berpartisipasi dalam melestarikan budaya.

Media komunikasi sebagai sebagai sebuah sarana untuk mengomunikasikan pesan terhadap upaya-upaya pelestarian budaya di Kotagede diharapkan akan memberikan pengaruh kepada masyarakat untuk ikut serta dalam upaya pengelolaan. Hal ini senada dengan yang diungkapkan oleh DeVito (2002:22) bahwa komunikasi mengacu pada tindakan, oleh satu orang atau lebih, yang mengirim dan menerima pesan yang terdistorsi oleh gangguan (noise), terjadi dalam suatu konteks tertentu, mempunyai pengaruh tertentu, dan ada kesempatan untuk melakukan umpan balik.

Adanya persepsi yang baik dari masyarakat terhadap penggunaan media-media komunikasi yang digunakan Organisasi Forum Joglo memberikan implikasi adanya dukungan masyarakat terhadap upaya 
pelestarian budaya itu sendiri. Mediamedia komunikasi yang ada, baik: leaflet, poster, jejaring sosial, maupun website kesemuanya dianggap sudah mampu menjadi sarana komunikasi dalam kegiatan pelestarian. Dengan adanya media komunikasi tersbut, masyarakat dapat mengetahui berbagai upaya pelestarian yang kemudian diharapkan dapat ber-partisipasi di dalamnya.

Dalam membuat sebuah media komunikasi yang digunakan, hendaknya Forum Joglo dapat memperhatikan karakteristik dari media komunikasi tersebut. Media komunikasi yang efektif akan memberikan umpan balik yang besar dari khalayak. Sementara pemilihan bahasa yang tepat juga harus diperhatikan, sehingga informasiinformasi yang disampaikan dapat diterima dengan baik oleh masyarakat. Hal tersebut, sebagaimana yang disampaikan oleh Luthans (2006:373), bahwa kemampuan informasi dalam media komunikasi dapat diukur dari empat faktor. Faktor pertama adalah umpan balik yang berkisar dari tingkat segera hingga sangat lambat. Kedua, saluran yang digunakan untuk membawa informasi, dari kombinasi audio dan visual sampai visual terbatas. Ketiga, jenis komunikasi, seperti personal dan nonpersonal. Keempat, sumber bahasa yang digunakan, termasuk bahasa tubuh bahasa alamiah, atau angka.

\section{KESIMPULAN}

Hasil penelitian menunjukkan bahwa persepsi masyarakat Kotagede terhadap penggunaan media komunikasi sebagai pelestarian budaya oleh
Organisasi Forum Joglo Kotagede Yogyakarta cenderung masuk kategori tinggi dengan kategori "sangat tinggi" sebanyak $33 \%$ dan "tinggi" sebanyak $43 \%$. Upaya-upaya pengembangan dari penggunaan media komunikasi perlu dilakukan oleh Organisasi Forum Joglo mengingat beberapa di antara media komunikasi yang digunakan masih banyak kekurangannya. Pengoptimalan media komunikasi yang digunakan merupakan sebuah keharusan yang hendaknya dilakukan. Selama ini penggunaan media komunikasi masih kurang intensif, sehingg intensitas penggunaan media tersebut perlu ditingkatkan. Hasil dari penelitian ini diharapkan dapat dijadikan acuan/dasar evaluasi bagi Organisasi Forum Joglo Kotagede Yogyakarta dalam melakukan pengelolaan media komunikasi sebagai kegiatan pelestarian budaya di Kotagede.

\section{DAFTAR PUSTAKA}

DeVito, Joseph A. (2002). Komunikasi Antar Manusia, Kuliah DasarEdisi Kelima. Jakarta: Professional Books.

Luthans, Freed. (2006). Perilaku Organisasi. Edisi 10. Yogyakarta:Andi Offset.

Mc Quail, Dennis. (1987). Teori Komunikasi Massa-Edisi Kedua. Jakarta: Erlangga.

http://www.initempatwisata.com/wisataindonesia/jogjakarta/inilah-5spot-wisata-kotagede-yogyakartapaling-menarik/3328/,

http://www.initempatwisata.com/wisataindonesia/jogjakarta/inilah-5spot-wisata-kotagede-yogyakartapaling-menarik/3328/, Diakses 10 Juli 2015 Pukul 14:04

http://www.kotagedeheritage.org/.

Diakses 11 Juli 2014, pukul 16.00. 


\section{UCAPAN TERIMA KASIH}

Redaksi Jurnal Humanika mengucapkan terima kasih atas partisipasi dan kesediaan Mitra Bestari untuk Volume. 15. Nomor. 1. September 2015, kepada;

Ajat Sudrajat (Universitas Negeri Yogyakarta) untuk artikel

1. "Islam Rahmah dan Wasathiyah (Paradigma Keberislaman Inklusif, Toleran dan Damai)" (Abd. Malik Usman)

2. "Etika Sosial dalam Kerukunan Umat Beragama (Studi Kasus di Desa Kotesan Kecamatan Prambanan Kabupaten Klaten Jawa Tengah)” (Andy Dermawan dan Zunly Nadia)

3. "Mencari Model Pendidikan Karakter" (Suparlan)

Suranto Aw (Universitas Negeri Yogyakarta) untuk artikel

1. "Persepsi Masyarakat Kotagede terhadap Pengunaan Media Komunikasi oleh Organisasi Forum Joglo untuk Pelestarian Budaya di Kotagede Yogyakarta” (Choirul Fajri)

2. "Implikasi Budaya Organisasi terhadap Pola Perilaku Komunikasi Kelompok Tani Sumber Rejeki” (Mariana Ulfah dan Siti Chotijah)

3. "Model Komunikasi "Wom” sebagai Strategi Pemasaran Efektif” (Dani Fadillah)

Yayan Suryana (Universitas Islam Negeri Sunan Kalijaga Yogyakarta) untuk artikel

1. "The Dialectics of Javanese and Islamic Cultures: an Introduction to Kuntowijoyo’s Thought” (Pradana Boy ZTF) 